\title{
Problematic parent-infant relationships in two-parent families: prevalence and risk factors in a Brazilian neighborhood
}

\author{
Relações problemáticas entre pais e criança em famílias com pai e mãe: \\ prevalência e fatores de risco em um bairro brasileiro
}

Olga Garcia Falceto, ${ }^{1}$ Elsa R. J. Giugliani, ${ }^{2}$ Carmen Luiza C. Fernandes ${ }^{3}$

\begin{abstract}
Introduction: Although the quality of parent-child relationships is known to be associated with the offspring's mental health, little is known about the prevalence of problematic relationships in this scenario. This cross-sectional study aims to investigate the prevalence and risk factors of different types of early parentinfant relationships in a Brazilian population group.

Methods: During 1 year, all families $(n=230)$ from an urban community of Porto Alegre, southern Brazil, with 4-month-old infants born in public hospitals were identified, and 148 were fully investigated by two family therapists. This study describes data on the 116 infants with two-parent families. Demographic, obstetric, and relational variables were collected through questionnaires and scales (ParentInfant Relationship Global Assessment Scale, Global Assessment of Relational Functioning, and Self-Report Questionnaire). Prevalence ratios were calculated, and Poisson regression with robust variance was performed to adjust for covariates.

Results: Almost $10 \%$ of mothers and $12 \%$ of fathers showed an at least significantly perturbed relationship with their 4-monthold infants. Inadequate mother-infant bonding coincided with evidence of paternal mental disorder, poor maternal social network, and no breastfeeding at 4 months. A problematic father-infant relationship was associated with a dysfunctional couple relationship and with low infant birth weight.

Conclusions: There is a high prevalence of early parent-child relationship problems, suggesting a need for health system interventions. Parent-infant relational problems are prevalent very early in life and more associated with other relational problems than with socioeconomic burden.

Keywords: Parent-infant problematic relationship, parenting, family relationship, child development, prevalence, relational problems.
\end{abstract}

\section{Resumo}

Introdução: Embora seja consenso que a qualidade das relações pais-filho influencia a saúde mental da prole, pouco se sabe sobre a prevalência de relações problemáticas nessa esfera. Este estudo transversal teve como objetivo investigar a prevalência e os fatores de risco de diferentes tipos de relações entre pais e lactentes em um bairro brasileiro.

Métodos: Durante 1 ano, todas as famílias $(n=230)$ residentes em uma comunidade urbana de Porto Alegre, sul do Brasil, com filhos de 4 meses de idade nascidos em hospitais públicos foram identificadas, e 148 foram investigadas em detalhe por dois terapeutas familiares. Este estudo descreve os dados dos 116 lactentes com famílias formadas por pai e mãe. Variáveis demográficas, obstétricas e relacionais foram coletadas através de questionários e escalas (Parent-Infant Relationship Global Assessment Scale, Global Assessment of Relational Functioning e Self-Report Questionnaire). Razões de prevalência foram calculadas, e a regressão de Poisson com variância robusta foi utilizada para ajuste de covariáveis.

Resultados: Quase $10 \%$ das mães e $12 \%$ dos pais mostraram uma relação significativamente perturbada com seus lactentes de 4 meses de idade. Vínculo inadequado entre mãe e lactente coincidiu com evidências de transtorno mental paterno, uma rede social de apoio insatisfatória por parte da mãe e interrupção do aleitamento materno antes dos 4 meses. Relação problemática entre o pai e o lactente associou-se com relação disfuncional do casal e com baixo peso do lactente ao nascimento.

Conclusões: Há uma alta prevalência de problemas nas relações precoces entre pais e filho, sugerindo a necessidade de intervenções do sistema de saúde. Problemas relacionais pais-filho são altamente prevalentes logo no início na vida do lactente e são mais associados a outros problemas relacionais do que a sobrecarga socioeconômica. Descritores: Relação problemática pais-filho, parentalidade, relações familiares, desenvolvimento infantil, prevalência, problemas relacionais.

\footnotetext{
${ }^{1}$ Department of Psychiatry, Faculdade de Medicina, Hospital de Clínicas de Porto Alegre (HCPA), Universidade Federal do Rio Grande do Sul (UFRGS), Porto Alegre, RS, Brazil. ${ }^{2}$ Department of Pediatrics, Faculdade de Medicina, HCPA, UFRGS. ${ }^{3}$ Family and Community Medicine, Grupo Hospitalar Conceição, Porto Alegre, RS, Brazil. Financial support: Fundo de Incentivo a Pesquisa e Eventos (FIPE), Hospital de Clínicas de Porto Alegre (HCPA).

Submitted Oct 14 2011, accepted for publication Dec 20 2011. No conflicts of interest declared concerning the publication of this article.

Suggested citation: Falceto OG, Giugliani ER, Fernandes CL. Problematic parent-infant relationships in two-parent families: prevalence and risk factors in a Brazilian neighborhood. Trends Psychiatry Psychother. 2012;34(3):139-46.
} 


\section{Introduction}

Few prevalence studies of parent-infant relational disorders are available in the literature, although all schools of psychology and child psychiatry emphasize that good parental care is associated with healthy emotional development of the offspring. Psychoanalysts have long emphasized the importance of a "good enough" early mother-child relationship in personality formation ${ }^{1}$ and described different types of mother-child bonding to be associated with different personality outcomes. ${ }^{2}$ However, they have given less emphasis to father-child relationships, focusing mainly on the impact of the father-adolescent relationship on adolescent development. ${ }^{3,4}$ Behavioral theories underline the influence of parenting patterns on children's behavioral outcomes. ${ }^{5}$ Family systems theory, in turn, concentrates on children's involvement in their parents marital conflicts as part of the etiology and resolution of behavioral and emotional problems. ${ }^{6}$

A recent Danish study on infant psychopathology in a sample representative of Copenhagen's population found a prevalence of $15.7 \%$ of problematic parent-child relationships at 6 months of age. ${ }^{7}$ However, little is known about specific risk factors involved. Socioeconomic burden is associated with more relational and psychiatric problems, but its direct association with early parent-child relationship problems is not evident. ${ }^{8}$ Parental mental disorders are known to associate with inadequate parent-child relationships and also with eventual mental illness in the offspring. ${ }^{9}$ Moreover, studies show that the quality of infant parenting is correlated with the quality of the couple's relationship. ${ }^{10-13}$ Longitudinal studies show deteriorating marital relationships following a child's birth, possibly because the parents focus on infant care and neglect their partner. ${ }^{14}$

A review article investigating whether fathering or mothering is more affected by divorce found that while limited evidence exists to suggest that fathering suffers more in the presence of marital conflict, divorce does seem to disturb fathering notably more than mothering. ${ }^{15}$ A meta-analysis of 11 studies concluded that the security of an infant's attachment to one parent was dependent upon its attachment to the other parent. ${ }^{16}$ Finally, a meta-analysis of 66 studies demonstrated that the mother's parenting behavior is positively correlated with the emotional and material support she receives. The sample was a relatively homogeneous population of white, middle class, married mothers with young children free of physical or mental disabilities. ${ }^{8}$

Although distressed mother-child and father-child relationships are a worldwide pediatric mental health concern, few studies have reported on the prevalence of these phenomena. Therefore, we designed a longitudinal naturalistic study with families of an urban neighborhood in southern Brazil to investigate the quality of parentinfant relationships and to identify possible associated risk factors. The present article describes results collected when the infants were 4 months old.

\section{Methods}

\section{Subjects}

We conducted a cross-sectional study in a neighborhood in Porto Alegre, a city of 1.5 million inhabitants located in southern Brazil.

This study is part of a larger longitudinal study. The broader research project was requested by family and community physicians from three multiprofessional outpatient clinics affiliated with a large public hospital called Grupo Hospitalar Conceição, which serves a community of 18,000 people. The selected neighborhood comprised mostly lower middle class families. All households had running water and electricity. Only the poorest houses lacked sewage disposal and garbage collection. Almost all streets in the neighborhood were paved, except for a few alleys (areas with greater risk of violence). These conditions are similar to those of many other Brazilian urban communities.

Families living in the studied neighborhood were identified based on birth records from all public hospitals in the city (at the time of the study, records from private hospitals were not available at the City Health Department system). When infants were 4 months old, a medical student visited the family's household to obtain identification data and permission to carry out a family interview. All families ( $n=230$ ) with a child born between November 1998 and December 1999 were visited (Figure 1). Two hundred fourteen families agreed with the collection of identification data. Of these, 163 were cohabiting two-parent families, i.e., the focus of this study. A total of 116 two-parent families $(71.2 \%)$ completed the study.

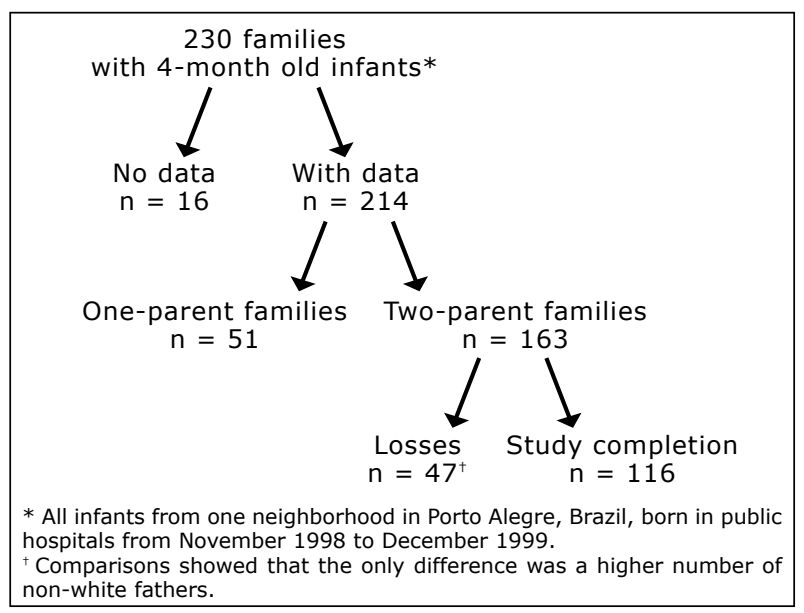

Figure 1 - Study population 


\section{Procedures}

Both parents signed an informed consent form agreeing to participate in the study. Each family was interviewed for approximately 2 hours by two experienced family therapists. The interviewers were coupled differently at each visit to prevent evaluation biases, and were blinded to the main objectives of the study. The interview consisted of an initial open conversation session often including grandparents, other relatives, and friends. During the second part of the interview, only parents and the child remained. The third part was an individual interview with each parent. In addition to data collection, the therapists observed the behaviors and interactions of family members. A medical student filmed the interviews. Throughout the study, two authors (O.G.F. and C.F.) kept regular meetings with the family therapists to ensure the collection of reliable information.

The research protocol was approved by the Research Ethics Committees at Grupo Hospitalar Conceição and Hospital de Clínicas de Porto Alegre.

\section{Interview}

We conducted semi-structured interviews including some open questions. The first part focused on the infant's birth and early life and on its impact on the life of the family. This part included questions about feeding habits and parental participation in the infant's care.

The second part of the interview focused on the couple's interpersonal relationship, on their view of the care each of them provided to the infant and on their relationship with their families and social networks. Since this was done in the presence of the infant, we could observe parent-infant interactions - for example, who responded to the baby's vocalizations or crying and what type of response was given. A genogram was drawn to better understand family relationship patterns. Open-ended questions were asked to both parents about family relationships and about medical and psychiatric family history. We questioned them about perceived similarities and differences in the way the couple and their families of origin related to each other.

The third part of the interview started with an open dialog with each individual parent. This was followed by structured questions about the pregnancy and delivery, the parent's relationship with the infant and with the partner, and the couple's sexual life and conflict-resolution strategies. Questions were aimed to know the family in depth and included topics such as domestic violence, relationship with relatives, friends, social network and healthcare and legal systems. The questions also dealt with personal history (of both the interviewee and his/ her partner), medical and psychiatric symptoms, alcohol and drug abuse, psychiatric hospitalizations, past and present use of psychotropic drugs, and legal problems. Through direct observation of their behaviors and through interviews and questionnaires, we focused on the following two aspects: 1) the care that each partner provided to the infant, 2) the couple's interpersonal relationship.

Each interviewer determined the ratings independently. Then the two interviewers discussed their evaluations and tried to reach consensus. Cases of disagreement were discussed with the principal investigator (O.G.F.) until a consensus was reached. When necessary, the video recording was examined.

\section{Instruments}

\section{Parent-infant relationship}

Father-infant and mother-infant relationships were rated through question answering and behavioral observation using the Zero to Three Diagnostic Manual Parent-Infant Relationship Global Assessment Scale (PIR-GAS). This scale is designed to identify and classify specific relationship disorders. For rating, we considered the total dynamics of the relationships, including parentchild interaction, parent and child levels of distress, their adaptive flexibility, and effects of the relationship on child's development. Intensity, frequency and duration of relationship difficulties were assessed. We asked each parent to describe their own relationship to the child. They also described how their partner cared for the infant and rated their level of satisfaction with the partner's care. Ratings were given as follows: $61-100$ for adapted relationships; 60 or less for relationships significantly perturbed or worse. We chose 60 as the cutoff point because this score indicates important difficulties between children and their parents in one or two areas of functioning for up to 1 month following a normal life event evoking stress. It is our experience as clinicians in that community that, when parents and children (and their support system) are well, these changes are very short lived (not over 1 week). ${ }^{17}$

\section{Couple relationship}

The mother and the father were asked to evaluate their interpersonal relationship, sexual life, and the frequency and severity of their conflicts. Their interactions were also observed throughout the interview. We rated the couple's functioning from 1 to 5 according to the Global Assessment of Relational Functioning (GARF) scale, from the Diagnostic and Statistical Manual of Mental Disorders, 4th edition, Text Revision (DSM-IV-TR). ${ }^{18}$ GARF determines the degree to which the family or the couple fulfills 
individual affective and operational needs of its members according to three areas of functioning: 1) problem solving; 2) family structure; and 3) affective expression among the couple. The scale assigns a global score of 5 (the relational unit is functioning in a satisfactory way according to the report of participants and the perspective of interviewers) to 1 (the relational unit has become too dysfunctional to guarantee the continuity of contact and attachment). In our analysis, groups were classified as without important difficulties (scores 4 or 5 ) and with moderate to severe difficulties (scores 1 to 3 ).

\section{Family of origin and social network relationships}

Using general information (including the genogram) and specific questions of the GARF scale, the interviewers rated the quality of the parents' relationship with their extended families and social network (neighbors, friends, health and school systems).

\section{Parents' mental health}

The interviewers assessed parental mental status using the Self-Report Questionnaire (SRQ-20), a selfadministered scale internationally used in epidemiologic studies and validated in Brazil, ${ }^{19}$ with cutoff scores of 7 or more for women and 5 or more for men indicating possible psychiatric disorder.

\section{Statistical analysis}

We used the Student's $t$ test and Fisher's exact test for the analysis of continuous demographic variables. For categorical data (sociodemographic, perinatal, mental health and relational data), we used a chi-square test with Yates's correction. Prevalence ratios (PR) and respective $95 \%$ confidence intervals $(95 \% \mathrm{CI})$ were calculated. Poisson regression with robust variance was used to adjust for the effects of possible confounding variables $(p<0.2)$. The following factors were entered into the model evaluating the presence of a distressed mother-infant relationship: father's schooling and work status, family income, breastfeeding at 4 months, presence of maternal or paternal mental disorder, couple's relationship, and mother's relationship with her extended family and social network. The following variables were included in the model evaluating the presence of a distressed father-infant relationship: father's schooling and work status, family income, infant birth weight, presence of paternal or maternal mental disorder, couple's relationship, and father's relationship with his extended family and social network.

An alpha error of $5 \%$ was chosen. The Statistical Package for the Social Sciences (SPSS) version 12.0 was used for statistical analyses.

\section{Results}

When comparing parent's age, schooling, skin color, occupation, household conditions, child delivery method, length of gestation, sex of the baby, birth weight and being firstborn between families that dropped out and those that completed the study, the only notable difference was the higher number of non-white fathers in the group that dropped out $(p<0.001)$.

Demographic and obstetric data are shown in Table 1 . The majority of the mothers and fathers were over 20 years of age. More than half of them were white, and $80 \%$ had completed 5 or more years of primary school. Most fathers had a steady job, and most mothers did not work outside the home. Around $40 \%$ of the babies were firstborn. The majority of the families earned more than 3 times the minimum wage (approximately 70 dollars at the time of the study), but around $8 \%$ lived below the poverty level. Babies were born mostly at term, through normal delivery, with adequate weight, and were not separated from their mothers at birth. Few fathers were able to participate in the delivery due to the way health care was organized at the time, but half of them went to at least one prenatal visit. Sixty-eight percent of the 4-month-olds were still breastfeeding.

Table 2 shows data on the quality of mother-infant and father-infant relationships: $9.5 \%$ of the mothers and $12.1 \%$ of the fathers had an at least significantly perturbed relationship with their child. Mothers were the primary caretakers in all families.

With regard to relational and mental health, the interviewers identified that: 1 ) $36.2 \%$ of the mothers and $17.4 \%$ of the fathers presented some evidence of a mental disorder; 2) $23.3 \%$ of the couple relationships were dysfunctional; 3) $28 \%$ of the families related poorly to their social network; and 4) $26 \%$ of the couples had a moderately or severely problematic relationship with the mother's extended family and $23.7 \%$ of them had problems with the father's family.

Results of the bivariate analysis of risk factors for distressed parent-infant relationships (sociodemographic, perinatal, mental health, and relationship variables) are shown in Table 3.

Adjustment for associations using Poisson regression (Table 4) demonstrated the following: 1) distressed mothering was statistically associated with mental disorder in the father $(P R=5.0 ; 95 \% C I$ 2.23-11.22), poor maternal social network (PR $=9.2 ; 95 \%$ CI 2.9828.27), and breastfeeding discontinuation at 4 months $(P R=2.7 ; 95 \% C I 1.30-5.50) ; 2)$ distressed fathering was associated with a dysfunctional couple relationship $(P R=8.2 ; 95 \% C I 1.61-41.64)$ and with low infant birth weight $(\mathrm{PR}=3.0 ; 95 \% \mathrm{CI} 1.10-8.12)$. 
Table 1 - Sample characteristics

\begin{tabular}{lcc}
\hline & Mothers (n = 116) & Fathers (n = 116) \\
\hline Age < 20 years & $22(19.0)$ & $9(7.8)$ \\
White skin color & $69(59.5)$ & $72(62.1)$ \\
Schooling < 5 years & $24(20.7)$ & $25(21.6)$ \\
Unemployed & $94(81.0)$ & $25(21.6)$ \\
Family/infant variables (n = 116) & $\mathbf{n ~ ( \% )}$ \\
Family income < 3 minimum wages* & $41(35.3)$ \\
Bad household conditions & $8(6.9)$ \\
$\geq 3$ children & $33(28.4)$ \\
Baby's male sex & $57(49.1)$ \\
Birth weight < 2500 g & $10(8.6)$ \\
Not firstborn & $69(59.5)$ \\
Cesarean delivery & $30(25.9)$ \\
Gestation < 37 weeks & $24(20.9)$ \\
Mother-infant separation due to continued maternal hospitalization after delivery & $7(6.0)$ \\
Father did not participate in the delivery & $110(94.8)$ \\
Father did not participate in pre-natal care & $62(53.4)$ \\
Stopped breastfeeding at 4 months & $39(33.6)$ \\
\hline
\end{tabular}

* One minimum wage $=$ US $\$ 70$.

Table 2 - Quality of mother-infant and father-infant relationships using PIR-GAS ratings

\begin{tabular}{lcc}
\hline & Mother-infant (n = 116) $\mathbf{n ~ ( \% )}$ & Father-infant (n = 116) $\mathbf{n}(\mathbf{\%})$ \\
\hline Well adapted & $22(19.0)$ & $21(18.1)$ \\
Adapted & $65(56.0)$ & $61(52.6)$ \\
Perturbed & $18(15.5)$ & $20(17.2)$ \\
Significantly perturbed & $2(1.7)$ & $6(5.2)$ \\
Distressed & $5(4.3)$ & $5(4.3)$ \\
Disturbed & $3(2.6)$ & $1(0.9)$ \\
Disordered & $1(0.9)$ & $2(1.7)$ \\
Severely disordered & 0 & 0 \\
Grossly impaired & 0 & 0 \\
\hline
\end{tabular}

PIR-GAS = Parent-Infant Relationship Global Assessment Scale - Diagnostic Classification: 0 to 3.

Table 3 - Crude associations of sociodemographic, perinatal, mental health, and relational factors with problematic mother-infant and father-infant relationships

\begin{tabular}{|c|c|c|c|c|}
\hline & \multicolumn{2}{|c|}{$\begin{array}{l}\text { Distressed mother-infant } \\
\text { relationship }\end{array}$} & \multicolumn{2}{|c|}{$\begin{array}{l}\text { Distressed father-infant } \\
\text { relationship }\end{array}$} \\
\hline & PR (95\%CI) & p* & PR (95\%CI) & p* \\
\hline Mother's schooling $<5$ years & $1.4(0.41-5.01)$ & 0.571 & $1.5(0.53-4.47)$ & 0.438 \\
\hline Father's schooling $<5$ years & $3.0(1.01-9.12)$ & 0.043 & $3.6(1.41-9.41)$ & 0.006 \\
\hline Mother without a steady job & $1.1(0.25-4.54)$ & 0.944 & $1.4(0.34-5.83)$ & 0.634 \\
\hline Father without a steady job & $3.03(1.01-9.12)$ & 0.043 & $3.6(1.41-9.41)$ & 0.006 \\
\hline Family income $<3$ minimum wages ${ }^{\dagger}$ & $2.2(0.71-6.76)$ & 0.161 & $2.4(0.91-6.55)$ & 0.069 \\
\hline Birth weight $<2500 \mathrm{~g}$ & $2.4(0.59-9.44)$ & 0.235 & $2.9(0.96-8.68)$ & 0.069 \\
\hline No breastfeeding at 4 months & $2.4(0.77-7.28)$ & 0.123 & $1.1(0.39-3.05)$ & 0.86 \\
\hline Mental disorder - Mother $\neq$ & $3.1(0.96-9.92)$ & 0.047 & $3.2(1.14-8.84)$ & 0.020 \\
\hline Mental disorder - Fatherł & $5.7(1.93-16.86)$ & 0.001 & $2.6(0.99-7.04)$ & 0.054 \\
\hline Couple with moderate to severe problems§ & $8.8(2.51-30.84)$ & $<0.001$ & $19.8(4.72-82.95)$ & $<0.001$ \\
\hline Poor social network & $11.8(2.70-51.74)$ & $<0.001$ & $4.7(1.71-13.03)$ & 0.001 \\
\hline Difficult relationship with mother's family of origin & $5.0(1.58-15.94)$ & 0.003 & $3.8(1.44-10.12)$ & 0.004 \\
\hline Difficult relationship with father's family of origin & $3.8(1.25-11.42)$ & 0.013 & $2.4(0.89-6.21)$ & 0.081 \\
\hline
\end{tabular}

$95 \% \mathrm{CI}=95 \%$ confidence interval; PR $=$ prevalence ratio.

* Chi square test, $\mathrm{p}<0.005$.

+ One minimum wage $=$ US\$ 70 .

* According to the Self-Report Questionnaire (SRQ-20).

$\S$ According to the Global Assessment of Relational Functioning (GARF) scale. 
Table 4 - Adjusted* association of sociodemographic, perinatal, mental health, and relational factors with problematic mother-infant and father-infant relationships

\begin{tabular}{|c|c|c|}
\hline & PR (IC 95\%) & $\mathbf{p}^{+}$ \\
\hline \multicolumn{3}{|l|}{ Distressed mother-infant relationship } \\
\hline No breastfeeding at 4 months & $2.7(1.30-5.50)$ & 0.007 \\
\hline Father schooling $<5$ years & $1.6(0.57-4.68)$ & 0.357 \\
\hline Father unemployed & $1.3(0.21-7.93)$ & 0.773 \\
\hline Family income $<3 \mathrm{MW}^{\ddagger}$ & $1.1(0.20-5.82)$ & 0.924 \\
\hline Maternal mental disorder $\S$ & $1.2(0.39-3.52)$ & 0.782 \\
\hline Paternal mental disorder $\S$ & $5.0(2.23-11.22)$ & $<0.001$ \\
\hline Couple with moderate/severe relationship problems & $2.6(0.68-9.91)$ & 0.163 \\
\hline Poor social network & $9.2(2.98-28.27)$ & $<0.001$ \\
\hline Difficult relationship with mother's family of origin & $1.2(0.35-4.08)$ & 0.778 \\
\hline \multicolumn{3}{|l|}{ Distressed father-infant relationship } \\
\hline Schooling $<5$ years & $1.8(0.77-3.99)$ & 0.181 \\
\hline Unemployed & $2.2(0.82-5.66)$ & 0.120 \\
\hline Family income $<3 \mathrm{MW}^{\ddagger}$ & $0.8(0.29-2.10)$ & 0.626 \\
\hline Birth weight $<2500 \mathrm{~g}$ & $3.0(1.10-8.12)$ & 0.032 \\
\hline Maternal mental disorder $§$ & $1.5(0.60-3.57)$ & 0.403 \\
\hline Paternal mental disorder $\S$ & $1.6(0.73-3.57)$ & 0.237 \\
\hline Couple with moderate/severe relationship problems & $8.2(1.61-41.64)$ & 0.011 \\
\hline Poor social network & $1.6(0.49-5.31)$ & 0.430 \\
\hline Difficult relationship with father's family of origin & $1.3(0.55-3.18)$ & 0.538 \\
\hline
\end{tabular}

* Poisson regression with robust variance.

${ }^{+}$Chi-square test.

₹ One minimum wage $=$ US $\$ 70$.

${ }^{\S}$ According to the Self-Report Questionnaire (SRQ-20).

\section{Discussion}

This study observed families at home in a neighborhood in southern Brazil. According to our data, almost $10 \%$ of the mothers and $12 \%$ of the fathers in two-parent families showed evidence of an at least significantly perturbed relationship with their 4-month-old babies. These results are similar to those of the Copenhagen Child Cohort CCC 2000 that found a prevalence of $15.7 \%$ of parenting problems when children were 6 months old - in our study, however, one-parent families were not included (about $24 \%$ of the total sample). ${ }^{7}$ These rates are very high, especially if we consider that inadequate parenting is likely to be associated with future child psychiatric and other health problems. 3,4,20-23

Contrary to our hypothesis, sociodemographic aspects traditionally thought to be risk factors ${ }^{8}$ for poor parentchild relationships (low schooling and income, no steady job) were not significantly associated with the outcome.

The mother-infant relationship was significantly more disturbed in the presence of a paternal mental disorder and a poor social network. Both conditions result in the mother not having adequate support for her mothering tasks. The association with early discontinuation of breastfeeding, also known to be associated with lack of support to the mother, is likely to be part of the same problem. With the present study design, it is not possible to define the direction of the association. ${ }^{24-26}$
This study, in consonance with the literature, ${ }^{7,8,15}$ showed that the presence of a dysfunctional couple relationship increased the probability of a distressed father-infant relationship. For example, a study of adolescent AfricanAmerican parents revealed that couple relationship was the main factor associated with the quality of father-child relationship. ${ }^{27}$ Also, other early parenting studies show a correlation between the quality of couple relationship and parental care. ${ }^{13}$ In addition, in our study, fathers were more likely to have problems relating to their babies when the latter were born underweight. The literature shows similar findings. ${ }^{28}$ Fathers may feel less competent to handle small, fragile, less responsive children. Their lack of resembling physical features may also alienate the father.

Contrary to some previous findings, we did not find an association between problematic father-infant relationship and paternal mental disorder. Possibly, when there is a good marital relationship, the father's decreased ability to respond to the infant's needs in this situation may be compensated by a mother that provides guidance to the father in the care of the child. We also expected that socioeconomic factors, such as not having a steady job, would be associated with an increased risk of poor fatherinfant relationships. However, the adjusted analysis did not confirm this hypothesis. It was also noteworthy that the number of children in the family did not associate with distressed parenting, possibly because, in our culture, older children usually help in the care of their siblings, 
facilitating the parents' role. Not surprisingly, the social network seemed to be more beneficial for the mother's than for the father's relationship with the infant.

We want to emphasize the high rates of parental mental disorder found in this study as well as in others that we have reviewed. In the studies conducted by Paulson et al., ${ }^{9}$ Areias et al., ${ }^{29}$ and Mathey et al., ${ }^{30}$ high prevalence rates - although lower than ours - of parental mental disorders were reported within 1 year of delivery. Their lower rates may be related to the better socioeconomic conditions found in their countries of origin, respectively, the USA, Portugal, and Australia. In our study, paternal mental health influenced the mother-infant relationship. However, we found no associations with the mother's mental health. This result would possibly be different if the children were older, as 4-month-old babies have simpler demands than older children and at this time the mother is usually well supported by the social network.

We consider that the results are robust because this was a populational study in which high PRs were found. Therefore, directions for future research and prevention can be outlined based on our findings. Perhaps the most important asset of this study is having been the first in the literature to assess the prevalence of parent-infant relationship problems examining families at home, using two trained mental health professionals who rated a scale by consensus. Parents were seen together along with their baby as well as individually. This methodology allowed for a comprehensive observation of relational patterns and the crosschecking of information. Although we did not use one of the published specific methodologies for observing dyadic and triadic parent-infant relationships, we believe that our methodology was clinically sound and that adequate care was taken to decrease biases of highly subjective variables.

One of the possible limitations of this research project was the loss of 47 two-parent families. When both parents are studied, it is harder to maintain their presence in the research. Nevertheless, comparisons between the demographic and obstetric characteristics of the two groups did not show any differences, suggesting that this limitation probably did not affect our results. Another limitation was the non inclusion of children born in private hospitals. As a result, we may infer that the families studied are likely to represent the urban, childrearing age, lower middle class population in Brazil and possibly in the rest of Latin America.

\section{Conclusions}

This study revealed that, in two-parent families, almost $10 \%$ of the mothers and $12 \%$ of the fathers showed evidence of an at least significantly perturbed relationship with their 4-month-old babies, underscoring the need for health interventions aimed specifically at this population. Parentinfant relational problems seem to be more associated with other relational problems than with socioeconomic burden.

\section{Recommendations}

Based on our findings, we recommend that health professionals be trained to evaluate the quality of mother-infant and father-infant relationships as well as to diagnose parents' mental disorders. We strongly suggest that fathers be a part of perinatal care. We hypothesize that, in the same manner as good early mother-infant bonding facilitates the later development of other healthy relationships, ${ }^{31}$ good early father-infant bonding may also protect the child. At present, fatherchild relationships have not been sufficiently studied. We are pursuing the study of this topic with a longitudinal follow-up of this population.

When the baby is born underweight, special programs should be designed for the fathers. Similarly, special attention should be given to mother-infant bonding in the presence of early weaning.

Finally, health care professionals should be trained to identify couple and social network relationship problems. Early detection of mental disorders and couple relationship dysfunction increases the chances of successfully treating them. During early parenthood, family relationships undergo many changes, and families are more flexible to accept professional interventions due to their increased parental sensitivity toward their babies. Young parents are eager to improve their parenting skills, but they need to be assisted by the health system. ${ }^{32}$

\section{Acknowledgments}

The authors acknowledge the financial support for data collection provided by Fundo de Incentivo a Pesquisa e Eventos (FIPE), Hospital de Clínicas de Porto Alegre (HCPA).

We wish to thank Jorma Piha, MD, PhD, and Enrique Falceto de Barros, MD, for their suggestions to the article.

Also, we are grateful to all members of the Study Group, namely Vanda Leite, MD, and Lisiane Perico, RN, from Grupo Hospitalar Conceição, and to the following individuals for their support with data collection and analysis: family therapists Alceu Correia Filho, Angela Diehl, Claudia Baratojo, Carmen Fernandes, Daniela Domingues, Denise Jong, Elizabeth Wartchow, Iara Sotto Mayor, Izabel Sperb, Jeane Laronda, José Ovidio 
Waldemar, Lucy Bugs, Mara Rossato, Marcia Tomazi, Maria Cristina Jung, Marina Netto, Paulina Silbert, and Regina Palma; medical students Anelise Cancelli, Antônio de Barros Lopes, Camila Giugliani, Carolina Alboim, Clarice Ritter, Daniel Barbosa, Guilherme Polanczyk, Jeber Ammar, Karina Marramarco, Letícia Quarti, Marta Pereira Lima, Martina Hoblik, Mauricio Kunz, Silvia Kelbert, and Tazio Vanni; and statisticians Mathias Bressel and Vania Naomi Hirakata.

\section{References}

1. Phillips A. Winnicott: an introduction. Br J Psychiatry. 1989; 155:612-8.

2. Ainsworth MD, Blehar, MC, Waters E, Wall S. Patterns of attachment: a psychological study of the strange situation. Hillsdale: Erlbaum; 1978.

3. Ramos SP. What can we learn from psychoanalysis and prospective studies about chemically dependent patients? Int J Psychoanal. 2004;85:467-88.

4. Ramos SP. Crack, the father, psychiatrists and psychoanalysts. Rev Psiquiatr Rio G Sul. 2008;30:99-100.

5. Newman K, Harrison L, Dashiff C, Davies S. Relationships between parenting styles and risk behaviors in adolescent health: an integrative literature review. Rev Lat Am Enfermagem. 2008;16:142-50.

6. Crockenberg $S$, Langrock $A$. The role of specific emotions in children's responses to interparental conflict: a test of the model. J Fam Psychol. 2001;15:163-82.

7. Skovgaard AM, Olsen EM, Christiansen E, Houmann T, Landorph SL, Jørgensen T, et al. Predictors (0-10 months) of psychopathology at age $11 / 2$ years - a general population study in The Copenhagen Child Cohort CCC 2000. J Child Psychol Psychiatry. 2008;49:553-62.

8. Andresen PA, Telleen SL. The relationship between social support and maternal behaviors and attitudes: a metaanalytic review. Am J Community Psychol. 1992;20:753-74.

9. Paulson JF, Dauber S, Leiferman JA. Individual and combined effects of postpartum depression in mothers and fathers on parenting behavior. Pediatrics. 2006;118:659-68.

10. Vandell DL, Hyde JS, Plant EA, Essex MJ. Fathers and "others" as infant-care providers: predictors of parents' emotional well-being. Merrill Palmer Q. 1997;43:361-85.

11. Rogers SJ, White LK. Satisfaction with parenting: the role of marital happiness, family structure, and parents' gender. J Marriage Fam. 1998;60:293-308.

12. Namba S, Tanaka K. Effects of support from and conflict with intimates on childcare stress: a longitudinal study. Jpn J Health Psychol. 1999;12:37-47.

13. Feldman R. Parents' convergence on sharing and marital satisfaction, father involvement, and parent-child relationship at the transition to parenthood. Infant Behav Dev. 2000;21:176-91.

14. Belsky J, Spanier GB, Rovine M. Stability and change in marriage across the transition to parenthood. J Marriage Fam. 1983;45:567-77.
15. Coiro MJ, Emery RE. Do marriage problems affect fathering more than mothering? A quantitative and qualitative review. Clin Child Fam Psychol Rev. 1998;1:23-40.

16. Fox NA, Kimmerly NL, Schafer WD. Attachment to mother/attachment to father: a meta-analysis. Child Dev. $1991 ; 62: 210-25$.

17. National Center for Clinical Infant Programs. Classificação diagnóstica: 0-3 - classificação diagnóstica de saúde mental e transtorno do desenvolvimento do bebê e da criança pequena. Porto Alegre: Artes Médicas; 1997.

18. American Psychiatric Association. Diagnostic and Statistical Manual of Mental Disorders, 4th edition, Text Revision (DSMIV-TR ${ }^{\mathrm{TM}}$ ). Washington: APA; 2000.

19. Mari JS, William P. A validity study of a psychiatric screening questionnaire (SRQ-20) in primary care in the city of São Paulo. Br J Psychiatry. 1986;148:23-6.

20. Aldous J, Mulligan GM. Father's child care and children's behavior problems. J Fam Issues. 2002;23:624-47.

21. Flouri $E$, Buchanan $A$. The role of father involvement in children's later mental health. J Adolesc. 2003;26:63-78.

22. Wood BL, Lim J, Miller BD, Cheah P, Zwetsch T, Ramesh S, et al. Testing the Biobehavioral Family Model in pediatric asthma: pathways of effect. Fam Process. 2008;47:21-40.

23. Bell BG, Belsky J. Parenting and children's cardiovascular functioning. Child Care Health Dev. 2008;34:194-203.

24. Sikorski J, Renfrew MJ, Pindoria S, Wade A. Support for breastfeeding mothers. Cochrane Database Syst Rev. 2002; (1):CD001141.

25. Falceto OG, Giugliani ERJ, Fernandes CL. Influence of parental mental health on early termination of breast-feeding: a casecontrol study. J Am Board Fam Pract. 2004;17:173-83.

26. Falceto OG, Giugliani ERJ, Fernandes CL. Couples' relationships and breastfeeding: is there an association? J Hum Lact. 2004;20:46-55.

27. Gavin LE, Black MM, Minor S, Abel Y, Papas MA, Bentley ME. Young, disadvantaged fathers' involvement with their infants: an ecological perspective. J Adolesc Health. 2002;31:266-76.

28. Feeley N, Gottlieb L, Zelkowitz P. Mothers and fathers of very low-birth weight infants: similarities and differences in the first year after birth. J Obstet Gynecol Neonatal Nurs. 2007;36:558-67.

29. Areias MEG, Kumar R, Barros H, Figueiredo E. Comparative incidence of depression in women and men during pregnancy and after childbirth: validation of the Edinburgh Postnatal Depression Scale in Portuguese mothers. $\mathrm{Br} \mathrm{J}$ Psychiatry. 1996; 169:30-5.

30. Matthey S, Barnett B, Ungerer J, Waters B. Paternal and maternal depressed mood during the transition to parenthood. J Affect Disord. 2000;60:75-85.

31. Bowlby J. Apego. São Paulo: Martins Fontes; 1984.

32. Matthey S, Barnett B. Parent-infant classes in the early postpartum period: need and participation by fathers and mothers. Infant Ment Health J. 1999;20:278-90.

\section{Correspondence}

Olga Garcia Falceto

Rua João Abbott, 451/402

90460-150 - Porto Alegre, RS - Brazil

Tel./Fax: +55-51-3332-1211

E-mail: olgafalceto@gmail.com 